\title{
Vientos de rebelión en América Latina: movimientos sociales anticapitalistas en la República de Bolivia
}

\author{
Belén Canavire \\ CONICET-Centro de Investigaciones sobre Ciencia y Cultura \\ belencanavire@hotmail.com
}

REsumen: A finales del siglo xx y principios del xxi, la realidad latinoamericana se vio agitada por la organización de diversos movimientos sociales que se extendieron a lo largo de este vasto territorio. En principio, estas acciones colectivas resistían a la brutal expansión de las políticas capitalistas neoliberales, pero, más tarde, se tornaron en formas de lucha política llegando a colisionar con el Estado. En los movimientos sociales acaecidos en la República de Bolivia se conjugaron la tradición, la cultura y la identidad de un pueblo, en defensa de sus derechos. En esta coyuntura de crisis del Estado, el rol de sumisión que tenían reservado las mayorías populares e indígenas se vio trastocado por la consagración del líder cocalero Evo Morales como presidente de la nación.

Palabras Clave: Bolivia, movimientos sociales, acción colectiva, cultura.

\section{Winds of REBELLION in LATin AMERICA: ANTI-CAPITAList SOCIAL MOVEMENTS IN THE REPUBLIC OF BOLIVIA}

ABSTRACT: In the late 20th and early 21 st centuries, Latin America was agitated by the organisation of various social movements which spread throughout this vast continent. At the beginning, these collective actions resisted the 
brutal expansion of neoliberal capitalist policies, but later turned into forms of political struggle which collided with the state. Social movements in the Republic of Bolivia combine a people's tradition, culture and identity, in defence of rights. At this critical juncture of the state, the submissive role usually assigned to the indigenous majority was disrupted by the coca leader Evo Morales' coming into power as president of the country.

KEYWords: Bolivia, social movements, collective action, culture.

INTRODUCCIÓN

Estos pueblos históricamente hemos sido marginados, humillados, odiados, despreciados y condenados a la extinción. Esa es nuestra historia; a estos pueblos jamás los reconocieron como seres humanos, siendo que estos pueblos son dueños absolutos de esta noble tierra y de sus recursos naturales.

Palabras de Evo Morales Ayma en la transmisión del mando presidencial, La Paz, 22 de enero de 2006.

Este artículo pretende explorar el proceso de transformación democrática en la república de Bolivia durante las últimas décadas del siglo xx y principios del siglo xxi. Con este propósito, analizaremos una arista de este fenómeno macrosocial: los "movimientos sociales" organizados en contra del modelo liberal-capitalista. Abordaremos estos sucesos a partir de un enfoque diferente de la política: la experiencia diaria de la gente. De este modo, atenderemos a los anhelos, miedos y desencantos de los individuos.

Las sublevaciones acaecidas en el país andino constituyen un episodio histórico propicio para explorar la dimensión subjetiva de la política. En el contexto de crisis económica e inestabilidad política que atravesaba la nación, las acciones represivas llevadas a cabo por el Estado -siguiendo mandatos neoliberales-, dieron como resultado un ciclo de protestas sociales destinadas a restituir las condiciones de vida del pueblo boliviano. Los insurrectos lucharon por la recuperación de sus recursos naturales y la revalorización de la "identidad indígena". En estas movilizaciones se vislumbró el resurgimiento de la nación boliviana desde sus sectores indígenas y populares. 


\section{Cuestiones TEÓRICAS}

El investigador Carlos Strasser expone tres impactos culturales que trasformaron la realidad latinoamericana desde inicios del siglo xIx: la incorporación de las doctrinas liberales al corpus ideológico preexistente; la cultura individualista o capitalismo salvaje; y la redefinición neoliberal del rol del Estado latinoamericano.

La introducción de las reformas económico-sociales neoliberales modificó ampliamente las economías latinoamericanas. Este proceso llevó a la descentralización del Estado, la privatización de las empresas públicas y el incremento del comercio internacional, entre otras radicales medidas. Desde entonces, la tendencia individualista propia de Occidente invadió la vida cotidiana de las personas, y este retraimiento al terreno individual llevó a una creciente desconfianza en los partidos políticos, las instituciones y el régimen democrático. Así pues, el ciudadano vacío de expectativas y falto de una cultura política definida, comenzó a distanciarse del ámbito político (Strasser 70-77). Este conjunto de condiciones fue dando forma al régimen democrático que se desplegaba en los países de América Latina.

En el contexto político actual, el concepto de democracia implica dos aspectos. A nivel sociológico, incluye sus "condiciones sociales de posibilidad"; en el aspecto político, refiere a su "configuración mixta" (Strasser 11). Sin embargo, a lo largo del tiempo, una cuestión ha perdurado como característica de la democracia: su radicación en un orden capitalista. Este "espíritu capitalista" alienta la supremacía de los intereses individuales por sobre el interés común, lo que genera múltiples fracturas en el tejido social. Entonces, paradójicamente, la democracia -promotora de igualdad política- pareciera tener que desarrollarse en un escenario contemporáneo de desigualdad social.

Por su parte, el politólogo Norbert Lechner considera al contexto posmoderno como propicio para disipar las ilusiones de omnipotencia concebidas en tiempos pasados, y explorar un aspecto opacado de

1 La democracia real contemporánea "mixta" está compuesta por diferentes formas políticas: la oligarquía, la burocracia, la tecnocracia, la partidocracia y el corporativismo (Strasser 58-59). 
la democracia: la experiencia diaria de la gente y su significación en contextos específicos. De este modo, presenta un mapa cognitivo-afectivo de la democracia, dando cuenta de un enfoque diferente de la política. Sobre este andamiaje teórico, aborda la cuestión del orden democrático, prestando particular atención al significado político que tienen los anhelos, miedos y desencantos de los individuos. Así, también destaca las complejas relaciones que se desarrollan entre democracia y transformación social.

Esta propuesta trata de explorar los procesos macrosociales a partir de un enfoque de tipo molecular: "la vida cotidiana". El ámbito cotidiano puede definirse en relación con lo no-cotidiano: lo novedoso, una ruptura, la continuidad interrumpida. Aunque, el ámbito cotidiano debe interpretarse de acuerdo a la significación colectiva de cada grupo social, de allí se desprende la existencia de "diferentes vidas cotidianas" condicionadas por sus respectivos entornos (Lechner 48).

Dar cuenta del proceso de democratización requiere atender a diversos aspectos: la credibilidad que la clase política pueda generar en los individuos; la identificación de la sociedad con el sistema político, y la pluralidad requerida por un orden democrático. El cumplimiento de estas condiciones promueve el ambiente de confianza que otorga legitimidad al sistema democrático.

Tiempo atrás, en los países del Cono Sur, estas circunstancias distaron de ser las ideales. Allí tuvieron lugar diversos golpes militares ${ }^{2}$ destinados a instalar "ley y orden" en sociedades sacudidas por periodos de cambios y movilizaciones sociales precedentes. Estos regímenes autoritarios produjeron una "cultura del miedo", fundando su poderío sobre los miedos $^{3}$-visibles y silenciados-de los ciudadanos. Además, el autoritarismo produjo la pérdida de referentes colectivos, el desvanecimiento de las expectativas hacia el futuro, y la alteración de la vida diaria de las sociedades latinoamericanas (Lechner 87-93).

2 Golpes militares en América Latina: Brasil (1964), Perú (1968), Chile (1973), Uruguay (1973), Argentina (1976).

3 Este sentimiento puede exteriorizarse cuando los hombres perciben en peligro su integridad física, o cuando se presentan amenazas para sus condiciones materiales de vida (Lechner 87). 
Actualmente, la posibilidad de alcanzar una cultura política democrática en América Latina requiere indagar en las condiciones en las que estas democracias se despliegan. En principio, el nacimiento de las repúblicas latinoamericanas bajo la influencia de los países dominantes indica el peso que las corrientes ideológicas extranjeras ejercieron (y ejercen) en estos territorios. Es así como los procesos internos de los países del Cono Sur no pueden explicarse sin el marco capitalista que los determina. Así también, el escenario contemporáneo se caracteriza por la concepción del "presente" como el único tiempo disponible. De esta forma, se borra el pasado y se anula el futuro, quedando el individuo sumergido en vaivenes de momentos efímeros. En concomitancia con esta idea neoliberal, se entiende la política como "mercado", generando así el descuido de un tema central para el desarrollo de la democracia: la pertenencia colectiva de los individuos (Lechner 64-70).

A estas circunstancias se suma un problema político de relevancia: la falta de referentes colectivos. Este fenómeno imposibilita la articulación de las diferencias sociales en búsqueda de una pluralidad nacional. Ahora bien, un intento de llenar este vacío es la producción de una nueva figura política: "el líder carismático" (Lechner 147). Diversas figuras presidenciales se han convertido en pilares del régimen democrático de sus países, y la lealtad que los ciudadanos depositan en ellos compensa la situación de incertidumbre en la que vive la comunidad. Este apoyo masivo al líder pareciera ser un camino prometedor para la afirmación de una identidad colectiva.

Como quedó expresado, las interacciones entre democracia y transformación social son múltiples. Por lo que aquí solo nos abocaremos a analizar una de sus aristas: los movimientos sociales. A tal fin, los consideramos:

Acciones colectivas con alta participación de base, que utilizan canales no institucionalizados y que, al mismo tiempo que van elaborando sus demandas, van encontrando formas de acción para expresarlas y se van constituyendo en sujetos colectivos, es decir, reconociéndose como grupo o categoría social (Jelin, citada en Ansaldi 18).

De acuerdo con este concepto, en el desarrollo de los movimientos sociales latinoamericanos es posible distinguir dos momentos históricos: el primero 
refiere a "formas de resistencia a la dominación política dictatorial y a los procesos de transición a la democracia"; el segundo es de "resistencia a los cambios regresivos en la estructura social generados por la aplicación de políticas neoliberales" (Ansaldi 21).

\section{MOVIMIENTOS SOCIALES EN BOLIVIA: SUCESOS Y PROTAGONISTAS}

A principios de siglo, los movimientos sociales desarrollados en la República de Bolivia en rechazo a la política neoliberal conjugaron distintos sectores: pobres urbanos, obreros, indígenas y jóvenes. Sus demandas se centraban en la recuperación de la soberanía estatal sobre los recursos naturales y el respeto a la dignidad.

A finales de los noventa, las deficiencias del sistema de agua en Cochabamba eran notorias. La red del suministro solo cubría a menos del $60 \%$ de la población. El resto de los habitantes se abastecía con sistemas autogestionados, o compraba agua a precios exorbitantes de camiones cisternas ("aguateros"). Esta cobertura deficiente de la red era exacerbada por una escasez de fuentes de agua. En estas condiciones críticas, los conflictos por los pozos $^{4}$ y los megaproyectos ${ }^{5}$ serían un preámbulo a los sucesos acaecidos durante el año 2000, en la denominada "Guerra del agua".

En busca de lucro en mercados de reciente creación, la empresa Bechtel de Estados Unidos llegó a Cochabamba para apoderarse del agua. Las instituciones financieras internacionales ${ }^{6}$ dieron el impulso al proceso de privatización, dotando al Estado boliviano de las políticas, agencias y estructuras para llevarlo a cabo. En septiembre de 1999 se firmó el contrato

4 Se trataba de una disputa de varios años entre el campo (comunidades y organizaciones rurales y semi-rurales) y la ciudad (SEMAPA y los políticos municipales y nacionales), cuyo nudo conflictivo era el control de las aguas subterráneas del valle central (Kruse 140).

$5 \quad$ Ante la crónica escasez de agua habían surgido varios proyectos de proporciones heroicas que buscaban proveer grandes cantidades de agua al valle. Tenían sus promotores en distintos grupos de poder local, cuyas fortunas políticas y económicas estaban estrechamente ligadas a los proyectos (Kruse 140).

$6 \quad$ El Banco Mundial y el Banco Interamericano de Desarrollo. 
de concesión ${ }^{7}$ para la privatización de SEMAPA (empresa local de agua), y se produjo la aprobación apresurada de la "Ley 2029 de Agua potable y Alcantarillado" que legalizaba y amparaba los negocios de Bechtel en el lugar. En la "Guerra del agua", las demandas de los consumidores y "regantes" se condensarían en torno a la anulación de ambos documentos.

Frente a estas circunstancias, el 28 de diciembre se desató un ciclo de protestas que se extendió durante los meses posteriores. Esta resistencia estuvo articulada por la Coordinadora de Defensa del Agua y de la Vida ${ }^{9}$ -que agrupaba a los regantes y la federación de fabriles- y el Comité de Defensa del Agua ${ }^{10}$.

La posición del gobierno en defensa de la inversión extrajera, y una serie de negociaciones frustradas, intensificaron el rechazo de las masas. Así pues, se produjeron bloqueos en el campo y en la ciudad, concentraciones y marchas, enfrentamientos feroces con la policía y la toma simbólica de las instalaciones de "Aguas del Tunari"11. El último enfrentamiento se produjo entre los autodenominados "guerreros del agua" -jóvenes marginales- y las fuerzas represivas, donde quedó claro que reprimir las manifestaciones involucraba una matanza.

Finalmente, el 10 de abril del 2000 el gobierno concedió todo lo que pedía la Coordinadora menos el levantamiento del estado de sitio. El acuerdo incluyó el retiro de Aguas del Tunari, la liberación de los detenidos, la atención de los heridos y la reformulación de la Ley 2029

El contrato prometía "tarifazos" o alzas dramáticas para los usuarios del agua. Así, también se establecían las bases para que Bechtel tomara control de los sistemas autogestionados construidos con el sacrificio de los pobladores, sin ninguna claridad sobre compensación ni respeto a sus derechos (Kruse 143).

8 Los diversos sistemas de riego - entendidos como la organización social de control del agua más la fuente de agua misma- son parte fundamental de la problemática del agua, y los "regantes" (pequeños propietarios) un actor central de la Guerra del agua (Kruse 135).

$9 \quad$ En octubre de 1999, los "regantes" convocaron a una reunión a la que asistieron más de cuarenta organizaciones sociales. Así nació la Coordinadora como un espacio de articulación de redes entre el campo y la ciudad (Kruse 153).

10 Integrado por profesionales, dirigentes de organizaciones barriales, comunales y medioambientalistas.

11 Un consorcio armado por Bechtel Enterprises. 
según las alternativas propuestas por los regantes y otras organizaciones sociales (Kruse 121-154).

Tras la elección de Gonzalo Sánchez de Losada como presidente de la nación en el 2002, los sectores populares y la población indígena (urbana y rural) articulaban sus reivindicaciones en torno a dos cuestiones: el uso de los recursos naturales y las autonomías regionales. De este modo, se iniciaba la llamada "Guerra del gas", cuyos principales sucesos tuvieron lugar en la ciudad de El Alto ${ }^{12}$ y barrios populares aledaños.

En agosto del mismo año, se realizaron marchas en oposición a la venta de gas a México y Estados Unidos, que propendía a la utilización de un puerto chileno. Posteriormente, en el 2003 las movilizaciones reclamaban la no inserción de Bolivia en el Acuerdo de Libre Comercio de las Américas (ALCA). Además, los activistas se resistían a las políticas del gobierno orientadas a reestructurar el sistema tributario.

La rebelión aymara ${ }^{13}$ y popular demostró su poderío en las masivas movilizaciones de octubre del 2003, a través de una huelga general, bloqueos en los caminos y resistencia civil. Luego de la masacre de cerca de cien personas, producto de los enfrentamientos con las fuerzas armadas, la contienda culminó con el derrocamiento de Sánchez de Losada. El vicepresidente Carlos Mesa, al asumir el mando, propuso dos reformas importantes: la revisión de la Ley de Hidrocarburos y la convocatoria a una Asamblea Constituyente para resolver la polémica de las autonomías (Ruiz Romero 51-52).

12 La ciudad de El Alto es un punto estratégico desde el cual es posible controlar los caminos que unen La Paz (capital administrativa de Bolivia) con otras ciudades. La identidad social de esta ciudad es plural y heterogénea debido a las numerosas migraciones que recibió a lo largo de su historia, aunque el origen indígena de sus habitantes funciona como "componente identitario homogeneizante" de la población (Puente y Longa 100). 13 Grupo étnico y familia lingüística asentados en el sur del Perú, norte de Chile y Altiplano de Bolivia, con extensiones hasta la frontera argentino-boliviana (Jujuy Diccionario General). 
EXPERIENCIAS DE ORGANIZACIÓN COLECTIVA Y REVALORIZACIÓN IDENTITARIA

Como señalamos más arriba, los regímenes autoritarios que se desarrollaron tiempo atrás en los países de América Latina generaron un contexto de inestabilidad y disciplinamiento social. De este modo, la pérdida de referentes colectivos y el desvanecimiento de las esperanzas impedían que la diversidad social fuera asumida como pluralidad.

A principios de siglo, la nación boliviana presentaba un escenario alternativo. Allí, la escalada represiva del Estado -para imponer mandatos neoliberales- fortaleció los lazos comunitarios de los distintos sectores que conformaban la resistencia: pobres urbanos, obreros, sindicales, jóvenes. La conjunción de las experiencias particulares y el reconocimiento de los ciudadanos en un espíritu de lucha nacionalista reactivaron la tradición organizativa social y sindical boliviana de épocas pasadas. Tanto en las contiendas de Cochabamba, como en los fuertes enfrentamientos sociales de El Alto, convergieron dos elementos: la organización colectiva y el sentido de dignidad.

Durante la Guerra del agua, la población estaba movilizada en todos sus sectores. La coalición que encabezó las protestas -la Coordinadora de Agua- propició la articulación de redes distintas pero potencialmente complementarias $^{14}$. La Coordinadora estableció una presencia visual innovadora cada semana en la plaza con una mesa de información para el público; se desplazó a los barrios y asociaciones de manera proactiva; se reapropió de los espacios públicos; ensayó nuevos mecanismos de democracia directa como la "Consulta Popular"15; y reinventó formas de

14 Los regantes, columna vertebral de la Coordinadora, aportaron una organización sólida y experimentada. Demostraron sus experiencias en conflictos previos, y supieron trabajar con técnicos y expertos. El Comité de Defensa hizo numerosas reuniones barriales, emitió comunicados de prensa, y estableció redes de contactos. La federación de fabriles aportó su experiencia comunicacional, su actitud de apertura y receptividad y el reconocimiento público como punto de encuentro (Kruse 154).

15 Esta "Consulta popular" movilizó a miles de activistas, parroquias y juntas vecinales, proponiendo así un ejercicio de democracia directa. En cientos de puntos de la ciudad se colocaron ánforas, donde más de 50.000 personas depositaron sus respuestas a tres preguntas sobre las tarifas, el contrato y las fuentes de agua (Kruse 148). 
movilizaciones como la toma de las oficinas de "Aguas del Tunari" (Kruse 157).

Asimismo, este accionar colectivo alentaba estrategias y prácticas autoorganizadas por los manifestantes. Es el caso de los "guerreros del agua", quienes organizaron puntos de control, sistemas de vigilancia, mecanismos de distribución de comida y primeros auxilios.

En la rebelión indígena y popular de 2003 -la Guerra del gas- la organización colectiva de los sectores "excluidos" se cristalizó en distintas formas. Al fragor de las confrontaciones, se produjeron recambios en las organizaciones barriales: en las asambleas populares se eligieron a muchos jóvenes como dirigentes vecinales en reemplazo de los antiguos representantes. Así también, frente al desabastecimiento de víveres - debido al bloqueo de las vías de acceso a la ciudad de La Paz- los sectores urbanos indígenas y mestizos relacionados con los mercados populares mostraron su capacidad de almacenaje y redistribución de los productos. En las calles y en las sedes sindicales se organizaron reuniones abiertas, donde el testimonio de la gente mayor sobre las experiencias de luchas pasadas alentaba la reacción de los más jóvenes (Ticona Alejo 187-190).

A partir del desenlace de este episodio histórico, los habitantes de El Alto, que hasta ese entonces eran calificados como de "segunda categoría" por sus compatriotas, lograron convertirse en símbolo de dignidad y lucha. Lo anterior se reflejaba en las consignas de las multitudinarias marchas: "El Alto de pie, nunca de rodillas"; "Abran cancha, abran cancha, que aquí llegan los alteños" (Ticona Alejo 193). De esta manera, la ciudad del altiplano se afianzaba como un nuevo actor social y político del país.

Es posible encontrar antecedentes históricos de las "prácticas colectivas" desarrolladas en los levantamientos de la Bolivia contemporánea. Particularmente en la lucha por la reconquista de la democracia a finales de los setenta e inicios de los ochenta ${ }^{16}$, donde la Central Obrera Boliviana (COB) encabezada por los mineros, el sindicalismo campesino y los movimientos sociales urbanos -a través de huelgas y movilizaciones masivas- puso en evidencia la incapacidad de la dictadura para lograr gobernabilidad y consenso.

16 Nos referimos a los conflictos que tuvieron lugar durante los gobiernos de facto de Hugo Banzer (1971-1978) y Luis García Meza (1980-1981). 
En América Latina emergió con fuerza un entramado social y organizativo basado en la vida comunitaria de los pueblos indígenas, que sirvió de sustento para la movilización social y política de muchos movimientos sociales en el continente. De este modo, se entrevió la sustitución de la clase obrera o trabajadora como vanguardia y protagonista principal de las luchas sociales, por movimientos indígenas que asumieron la conducción y aglutinaron a los otros sectores detrás suyo.

En las insurrecciones bolivianas, la organización colectiva de los distintos sectores - pobres, indígenas, jóvenes, obreros- da cuenta de la recuperación del término "indio" como elemento cohesionador de una identidad nacional y popular amplia, que articula varias memorias: una memoria larga (anticolonial), una memoria intermedia (nacionalista revolucionaria) y una memoria corta (antineoliberal) (Stefanoni 25).

Cabe recordar que esta eclosión del movimiento indígena también tuvo lugar en países como Ecuador y México. En la década de los noventa, el conjunto de la sociedad ecuatoriana y las propias organizaciones de izquierda fueron removidas por la consolidación y el protagonismo del movimiento indígena. Las exigencias principales giraban en torno a: demandas de carácter reivindicativo (lucha legitimada por su alcance territorial) y políticas globales de interés del conjunto de la sociedad, como el reconocimiento del carácter multicultural y plurinacional del país. En México, hacia 1994 el Ejército Zapatista de Liberación Nacional (EZLN) habría ordenado crear 38 "municipios rebeldes" como una estrategia para "romper el cerco" militar puesto por el ejército mexicano. El EZLN demandaba derechos sociales, económicos y políticos, y reclamaba formas alternativas de inclusión en la nación.

Los actores colectivos de los alzamientos en Bolivia demandaron una reforma política y una transformación del modelo económico. Los desenlaces de estas insurrecciones señalaron el derrumbe del monopolio de la lógica liberal-capitalista sobre la sociedad boliviana y el resurgimiento de la perspectiva "indígena". La consideración de los movimientos sociales bolivianos, en tanto procesos microsociales, constituye un punto de partida en la comprensión de un fenómeno de mayor amplitud: el desarrollo del orden democrático nacional. 
UNA CULTURA ANCESTRAL ENTRE VAIVENES POSMODERNOS

Como quedó señalado, la dinámica interna de los países latinoamericanos se encuentra condicionada por la lógica capitalista, así como sus procesos de democratización fueron teñidos por el ambiente ideológico-cultural internacional.

Hacia 1990 se firmó el denominado "Consenso de Washington", una lista de políticas económicas elaboradas por Estados Unidos para impulsar el crecimiento de los países de América Latina. De este menú devinieron las reformas de Estado neoliberales que incluían: "descentralizar el Estado nacional, atraer las inversiones, privatizar las empresas públicas y beneficiar la competitividad en el comercio internacional" (Strasser 76). La crisis del Estado nacional-popular latinoamericano constituyó el espacio propicio para el ingreso de los lineamientos económico-sociales neoliberales y las transformaciones propagadas por la "globalización". Estas nuevas condiciones impactaron de manera profunda en la macroeconomía de las repúblicas del Cono Sur, y resquebrajaron los lazos sociales preexistentes (Strasser 71).

En Bolivia, así como en los demás Estados de América Latina, se ha construido un modelo liberal caracterizado por la hegemonía de la cultura occidental, lo que ha generado: la degradación de las culturas originarias, el deterioro de los sistemas políticos y la imposición de un sistema jurídico que favorece los intereses del mercado, privando a los habitantes de sus medios de subsistencia (Svampa y Stefanoni 191).

De acuerdo al último Censo Nacional de Bolivia del 2001, se contabilizaron como pobres a 4,7 millones de personas, lo que equivale al $55 \%$ de la población total ${ }^{17}$. Frente a las demandas sociales, el actual presidente Evo Morales ${ }^{18}$ impulsa un modelo económico-social con

Datos del CENSO 2001. Bolivia. Consultado el 9 de febrero de 2010 en Instituto Nacional de Estadística: http://www.ine.gov.bo/html.

18 Evo Morales proviene de un pequeño pueblo del altiplano orureño. Su carrera sindical comenzó en 1981 cuando fue nombrado secretario de deportes de su sindicato, y diez años más tarde llegó a ocupar una banca en el Congreso, representando a la "Izquierda Unida". Finalmente, en las elecciones de diciembre del 2005, Evo Morales representando al MAS-IPSP, fue consagrado presidente de la República (Stefanoni 68). 
dos cuestiones centrales: la nacionalización de los hidrocarburos y la industrialización del país.

El apoyo masivo de la población a la figura de Evo Morales, en tanto referente colectivo, permite hablar de un "carisma situacional" (Lechner 150). La legitimidad inédita de este líder deviene principalmente de tres fuentes: la incorporación de los intelectuales bolivianos a su partido; su relación con las organizaciones sociales campesinas y el lugar otorgado a la comunidad indígena en las políticas gubernamentales.

El cultivo de la hoja de coca también ha sido un terreno invadido por las directrices neoliberales. Desde finales del siglo xx, Estados Unidos comenzó a implementar políticas de erradicación destinadas a eliminar el narcotráfico. Estas disposiciones afectaban gravemente la labor de los cocaleros $^{19}$. En 1992 se consolidó el movimiento campesino-indígena que reivindicaba a la coca como "una hoja sagrada, representativa de la cultura andina". La incesante lucha en defensa de la coca alcanzó su máxima expresión en el año 1994 cuando se realizó la "Marcha por la Vida, la Coca y la Soberanía" (Do Alto 37). Más adelante, Evo Morales en su primer discurso presidencial dedicó un apartado especial al cultivo de la coca y proclamó: "queremos decirles a la comunidad internacional (...) hay que acabar con la cocaína. Pero no habrá coca cero sino cocaína cero, narcotráfico cero" (Citado en Svampa y Stefanoni 245).

Frente a las directrices posmodernas, en Bolivia aparecieron destellos de una realidad distinta. En oposición a la concepción capitalista del presente como el "único tiempo disponible", en el país andino se produjo la revitalización de las memorias sobre grandes luchas del pasado -como las rebeliones de Tupac Katari ${ }^{20}$ y Zárate Willka ${ }^{21}$ - presentes en el cotidiano de muchos movimientos indígenas. Así también, frente a la idea neoliberal de la política como "mercado" que socava la pertenencia colectiva de los individuos, en las contiendas del altiplano se recuperó la antigua organización comunitaria heredada de los antepasados indígenas. 


\section{A MODO DE CONCLUSIÓN}

En Bolivia, los gobiernos que se sucedieron a lo largo de la historia se dedicaron a negociar con las riquezas naturales del país, deteriorando progresivamente las condiciones de vida del pueblo boliviano. A lo que se sumaba el desinterés político por resolver la cuestión de los "pueblos indígenas excluidos" en su propia nación. Durante las últimas décadas del siglo xx, este contexto de crisis fue propicio para el desarrollo de la lógica liberal-capitalista impuesta por la cultura occidental.

En este escenario de inestabilidad general -donde los mandatos neoliberales erosionaban las culturas originarias y los sistemas políticos del país- estallaron insurrecciones populares en rechazo a las políticas neoliberales, el saqueo de los recursos naturales y la violación de los derechos humanos. Durante las jornadas de lucha, donde participaron pobres urbanos, indígenas (urbanos y rurales), trabajadores y jóvenes, se construyeron marcos de acción colectiva. Asimismo, la organización de la rebelión a partir de prácticas comunitarias heredadas puso de manifiesto la revalorización del pasado indígena. La reflexión de los movimientos sociales bolivianos, como procesos microsociales, nos permitió interpretar un fenómeno más amplio: el derrumbe de la hegemonía liberal-capitalista sobre el orden social boliviano.

Los habitantes bolivianos - con su tradición indígena ancestral- fueron históricamente sometidos a una discriminación violenta. Sin embargo, durante el último período, el pueblo boliviano ha tenido la oportunidad de transformar su pasado sombrío, dando lugar al resurgimiento de la perspectiva indígena. Asimismo, el reconocimiento del "otro" como partícipe de la producción de un horizonte común, permitió a los bolivianos replantearse qué sociedad deseaban y hasta dónde era posible construirla.

En la actualidad, el presidente Evo Morales es un líder carismático que cuenta con el apoyo de la mayoría de la población. A fin de revertir la situación social de pobreza, promueve una ideología nacional-popular que incluye: la nacionalización de los recursos naturales y un proyecto destinado a construir un país productivo mediante el fortalecimiento de alianzas de cooperación internacionales. 
El clamor del pueblo boliviano por una transformación social y democrática se hace oír cada vez más fuerte, resta conocer si los vientos de esta rebelión persistirán en los avatares del tiempo.

\section{BiBLIOGRAFÍA}

AA.VV.Jujuy Diccionario General. San Salvador de Jujuy: Ediciones Gobierno de la Provincia de Jujuy, 1992. Impreso.

Ansaldi, Waldo. "Quedarse afuera, ladrando como perros a los muros. Protesta y movimientos sociales en América Latina en la bisagra de los siglos xx y xxI". Anuario 21 (2005-2006): 15-61. Impreso.

Calderón Gutiérrez, Fernando y Alicia Szmukler. La política en las calles. La Paz: CERES/ UASB/ Plural, 2000. Impreso.

Do Alto, Hervé. “'Cuando el nacionalismo se pone el poncho'. Una mirada retrospectiva a la etnicidad y la clase en el movimiento popular boliviano (1952-2007)". Bolivia: memoria, insurgencia y movimientos sociales. Maristella Svampa y Pablo Stefanoni (eds.). Buenos Aires: Ed. El Colectivo/CLACSO/OSAL, 2007. 21-53. Impreso.

Instituto Nacional de Estadísticas. Datos del Censo 2001. Consultado el 9 de febrero de $2010<$ http://www.ine.gov.bo/html>. Web.

Kruse, Thomas. 'La 'Guerra del Agua' en Cochabamba, Bolivia: terrenos complejos, convergencias nuevas". Sindicatos y nuevos movimientos sociales en América Latina. Enrique de la Garza Toledo, comp. Buenos Aires: CLACSO, 2005. 85-119. Impreso.

Lechner, Norbert. Los patios interiores de la democracia. Subjetividad y politica. Santiago de Chile: FLACSO, 1988. Impreso.

Massal, Julie y Marcelo Bonilla. Los movimientos sociales en las democracias andinas. Quito: FLACSO, 2000. Impreso.

Mayorga, René Antonio, comp. Democracia a la deriva. Dilemas de la participación y la concertación social en Bolivia. La Paz: CERES/CLACSO. Impreso.

Monasterios, Karin, Pablo Stefanoni y Hervé Do Alto, eds. Reinventando la nación en Bolivia. Movimientos sociales, Estado y poscolonialidad. La Paz: CLACSO/Plural, 2007. Impreso. 
Puente, Florencia y Francisco Longa. "El Alto: los dilemas del indigenismo urbano. Entre la insurrección y el clientelismo". Bolivia: memoria, insurgencia y movimientos sociales. Maristella Svampa y Pablo Stefanoni, eds. Buenos Aires: Ed. El Colectivo/CLACSO/OSAL, 2007. 97-123. Impreso.

Ruiz Romero, Mariana. "Nuevos actores locales en el ámbito nacional. Tarija-Bolivia: autonomías regionales y políticas nacionales. El caso del gas natural, 2002-2004”. Tesis de Maestría en Relaciones Internacionales. Universidad Nacional de Córdoba, 2006. Impreso.

Sandoval, Godofredo y Virginia Ayllon. La memoria de las ciudades. Bibliografia urbana de Bolivia 1952-1991. La Paz: CEP/ILDIS, 1992. Impreso.

Stefanoni, Pablo. "Bolivia, bajo el signo del nacionalismo indígena. Seis preguntas y seis respuestas sobre el gobierno de Evo Morales". Reinventando la nación en Bolivia. Movimientos sociales, Estado y poscolonialidad. La Paz: CLACSO/Plural, 2007. 23-46. Impreso.

“Las tres fronteras de la 'revolución' de Evo Morales. Neodesarrollismo, decisionismo, multiculturalismo". Bolivia: memoria, insurgencia y movimientos sociales. Buenos Aires: El Colectivo, 2007. 67-96. Impreso.

Strasser, Carlos. Democracia y desigualdad. Sobre la "democracia real" a fines del siglo XX. Buenos Aires: CLACSO/ASDI, 1999. Impreso.

Svampa, Maristella y Pablo Stefanoni, eds. Bolivia: memoria, insurgencia y movimientos sociales. Buenos Aires: El Colectivo, 2007. Impreso.

Ticona Alejo, Esteban. "La rebelión aymara y popular de octubre de 2003. Una aproximación desde algunos barrios paceños de La Paz, Bolivia”. Pueblos indígenas, Estado y democracia. Pablo Dávalos, comp. Buenos Aires: CLACSO, 2005. Impreso. 